\title{
AMELIORATIVE EFFECTS OF VITAMINS C AND E ON TENOFOVIR/NEVIRAPINE-INDUCED HEPATORENAL OXIDATIVE STRESS IN ALBINO RATS
}

\begin{abstract}
Elias Adikwu²*, Apiakise Williams ${ }^{2}$
1Department of

Pharmacology, Faculty of

Basic Medical Sciences, University of Port Harcourt, Choba, P.M.B 5323 Rivers

State Nigeria

2Department of Community Health Sciences, College of Health Technology, Otuogidi, Bayelsa State, Nigeria. 562103.

Submitted: 05-8-2016

Revised: $15-09-2016$

Accepted: $13-10-2016$

*Corresponding author Adikwu Elias

Email:

adikwuelias@yahoo.com

ABSTRACT

Oxidative stress has been implicated in xenobiotic-induced hepatorenal toxicity. This research was designed to investigate the effects of vitamins $C$ and $E$ on tenofovir/nevirapine-induced liver and kidney levels of superoxide dismutase (SOD), glutathione (GSH), catalase (CAT) and malondialdehyde (MDA) in male albino rats. Forty five male albino rats were used for this study. The rats were divided into groups A-I of 5 rats each. Group A (placebo control) and group B (solvent control) were orally treated with water and arachis oil respectively. Groups C $F$ were orally treated with vitamins $C, E$, combined doses of vitamins $C$ and $E$, and tenofovir/nevirapine, respectively. Groups G-I were pretreated with vitamins $C, E$ and combined doses of vitamins $\mathrm{C}$ and $\mathrm{E}$ prior to treatment with tenofovir/nevirapine, respectively. Rats were sacrificed after treatment for 30 days; liver and kidneys were collected and evaluated for the above parameters. Significant $(p<0.05)$ increases in the baseline levels of liver and kidney SOD, GSH, and CAT with decreases in MDA levels were obtained in vitamins $C$ and $E$ treated rats when compared to control. However, treatment with tenofovir/ nevirapine significantly $(p<0.05)$ decreased liver and kidney SOD, GSH, and CAT levels with increases in MDA levels when compared to control. However, all tenofovir/nevirapine -induced alterations were abrogated in rats pretreated vitamins $C$ and $E$. Abrogation was most pronounced in rats pretreated with combined doses of vitamins $C$ and $E$. The observations in the present study could be attributed to the inhibitory effects of vitamins $C$ and $E$ on the oxidative activity of tenofovir/nevirapine in the liver and kidneys of treated rats.
\end{abstract}

Keywords: tenofovir, nevirapine, liver, kidney, oxidative stress, antioxidants, rats

\section{INTRODUCTION}

Liver and kidney are vital organs for human existence with both anatomical and physiological functions. The liver functions in transforming and detoxifying drugs and metabolites. It also produces different types of plasma proteins, such as albumin, which are delivered into the blood, as well as metabolites that are constituents of the bile (Arias et al., 1997; Junqueira and Carneiro, 2003; Sasse et al., 2013). Kidneys are organs that serve several essential regulatory functions which include drug excretion and the removal of waste products. They also serve homeostatic functions such as the regulation of electrolytes, maintenance of acid-base balance and regulation of blood pressure (Raghavendra, 2013). Kidney and liver contain antioxidants, which protect them from free radical-induced oxidative damage. The constant involvement of the liver and kidney in drug biotransformation and excretion respectively could lead to druginduced oxidative stress, characterized by depletion of antioxidants and consequently damage to their architecture, thereby impairing their functions (Woodward et al., 2009; An et al., 2009).

The use of highly active antiretroviral therapy, which involves the combination of three or more classes of antiretroviral drugs, has contributed to a drastic decrease in morbidity and mortality associated with human 
immunodeficiency virus ( $\mathrm{Li}$ et al., 1998). However, the long-term use of highly active antiretroviral therapy could place more toxicological burden on the liver and kidney (Johnson et al., 2004). Tenofovir/nevirapine (TDF/NVP) combination is a component of highly active antiretroviral therapy used as part of all preferred regimens for antiretroviral-naive adults and adolescents. The use of TDF/NVP has contributed to increase in life expectancy, decrease in acquired immune deficiency syndrome defining conditions, and marked immunological improvements in patients living with human immunodeficiency virus (Hammer et al., 2008; Gallant and Deresinski, 2003) However, tenofovir and nevirapine could be associated with nephrotoxicity and hepatotoxicity, respectively (Adaramoye et al., 2013; Ramamoorthy et al., 2014) therefore, concurrent use could precipitate hepatorenal toxicity characterized by oxidative stress.

Vitamins $\mathrm{C}$ and $\mathrm{E}$ are antioxidants with activities against drug-induced oxidative stress in biological systems (Sies, 1985). Vitamin C is a water-soluble, non-enzymatic antioxidant in plasma and tissues. It is a potent reducing agent that readily donates electrons to recipient molecules (Combs and Gerald, 2013). It protects biomolecules from damage by reactive oxygen species and also participates in the recycling of other antioxidants such as vitamin $\mathrm{E}$ (Carr, and Frei, 1999). Vitamin $\mathrm{E}$ is an important lipid-soluble antioxidant that protects membranes from oxidation by reacting with lipid radicals produced in the lipid peroxidation chain reaction. The removal of free radical intermediates by vitamin $\mathrm{E}$ can prevent or terminate the propagation of lipid peroxidation chain reaction. Termination of lipid peroxidation chain reaction by vitamin $\mathrm{E}$ produces oxidized alpha tocopheroxyl radicals, which can be recycled back to the active reduced form by other antioxidants such as vitamin C (Herrera, and. Barbas, 2001; Packer et al ., 2001). Vitamins $C$ and $E$ are known to have sparing effects on each other and synergy in antioxidant activity has been reported with concurrent use (Traber and Atkinson, 2007). Furthermore, in our previous study, vitamins $\mathrm{C}$ and $\mathrm{E}$ pretreatments attenuated TDF/NVPinduced alterations in biomarkers of liver and kidney functions in albino rats (Adikwu et al., 2016). This study was aimed at investigating the effects of vitamins $\mathrm{C}$ and $\mathrm{E}$ on the baseline and TDF/NVP-induced liver and kidney levels of superoxide dismutase (SOD), glutathione (GSH), catalase (CAT) and malondialdehyde (MDA) in male albino rats.

\section{MATERIALS AND METHODS \\ Animals}

Rats of average weight $330 \pm 5 \mathrm{~g}$ used for this study were obtained from the animal house of the Department of Pharmacology and Toxicology Madonna University, Elele, Rivers State. Rats were allowed to acclimatize for 14 day, and had free access to food and water ad libitum.

\section{Drugs}

Pure samples of tenofovir, nevirapine, vitamins $\mathrm{E}$ and $\mathrm{C}$ were purchased from Shijiazhuang AO pharm Import and Export Trading Co., Ltd, China. Tenofovir and nevirapine powder were suspended in arachis oil while vitamin $\mathrm{C}$ was dissolved in water. Vitamins C, $20 \mathrm{mg} / \mathrm{kg} / \mathrm{day}$, vitamin E, $20 \mathrm{mg} / \mathrm{kg} /$ day (BNF, 1999) and 90/60 $\mathrm{mg} / \mathrm{kg} /$ day of TDF/NVP (Adikwu et al., 2016) were used for this study.

\section{Experimental design}

The rats were divided into groups A-I of 5 rats each. Group A (placebo control) and group B (solvent control) were orally treated with water and arachis oil respectively. Groups C-F were orally treated with vitamins $\mathrm{C}, \mathrm{E}$, vitamins $\mathrm{C}$ and $\mathrm{E}$, and TDF/NVP respectively. Groups G-I were pretreated with vitamins C, E and combined doses of vitamins $C$ and $E$ prior to treatment with TDF/NVP respectively. Rats in all groups were once daily treated for 30 days.

\section{Collection of sample}

Rats were sacrificed with the aid of diethyl ether. Rats were dissected; kidney and liver were collected and washed in an ice cold $1.15 \%$ KCL solution. Kidney and liver were then homogenized with $0.1 \mathrm{M}$ phosphate buffer $(\mathrm{pH}$ 7.2). The resulting homogenates were centrifuge at $2500 \mathrm{rmp}$ speed for $15 \mathrm{~min}$ and the supernatants decanted and used for the evaluation of oxidative stress indices. 
Table I. Effects of treatments with vitamins $\mathrm{C}$ and $\mathrm{E}$ on baseline liver oxidative stress indices of male Albino Rats

\begin{tabular}{lllll}
\hline Dose & \multicolumn{1}{c}{ MDA } & \multicolumn{1}{c}{ SOD } & \multicolumn{1}{c}{ CAT } & GSH \\
\hline Control & $0.74 \pm 0.08$ & $10.30 \pm 1.24$ & $14.19 \pm 1.13$ & $8.52 \pm 0.24$ \\
Vit C $(20 \mathrm{mg} / \mathrm{kg})$ & $0.53 \pm 0.05^{*}$ & $14.50 \pm 2.34^{*}$ & $22.10 \pm 3.12^{*}$ & $13.00 \pm 3.15^{*}$ \\
Vit E $(20 \mathrm{mg} / \mathrm{kg})$ & $0.50 \pm 0.09^{*}$ & $16.53 \pm 2.02^{*}$ & $25.35 \pm 3.65^{*}$ & $15.20 \pm 2.33^{*}$ \\
Vit C $+\mathrm{E}$ & $0.31 \pm 0.03^{* *}$ & $28.20 \pm 3.12^{* *}$ & $47.00 \pm 3.27^{* *}$ & $30.1 \pm 3.38^{* *}$ \\
\hline
\end{tabular}

$\mathrm{MDA}=$ Malondialdehyde. $\mathrm{SOD}=$ Superoxide dismutase. $\mathrm{CAT}=$ Catalase. $\mathrm{GSH}=$ Glutathione. Data are expressed as mean \pm SEM. $\mathrm{n}=5$. * Significant $(p<0.05)$ difference when compared to control. ** Significant $(p<0.05)$ difference when compared to treatments with individual doses of vitamins $\mathrm{C}$ and $\mathrm{E}$

Table II. Effects of treatments with vitamins $\mathrm{C}$ and $\mathrm{E}$ on baseline kidney oxidative stress indices of male albino Rats

\begin{tabular}{lllll}
\hline Dose & \multicolumn{1}{c}{ MDA } & \multicolumn{1}{c}{ SOD } & \multicolumn{1}{c}{ CAT } & GSH \\
\hline Control & $0.73 \pm 0.04$ & $10.10 \pm 0.15$ & $15.2 \pm 1.16$ & $8.50 \pm 1.02$ \\
Vit C $(20 \mathrm{mg} / \mathrm{kg})$ & $0.52 \pm 0.04^{*}$ & $14.55 \pm 1.14^{*}$ & $22.30 \pm 5.10^{*}$ & $14.20 \pm 1.04^{*}$ \\
Vit E $(20 \mathrm{mg} / \mathrm{kg})$ & $0.51 \pm 0.01^{*}$ & $14.72 \pm 1.19^{*}$ & $24.71 \pm 3.36^{*}$ & $16.50 \pm 2.12^{*}$ \\
Vit C+E & $0.29 \pm 0.06^{* *}$ & $23.74 \pm 2.67^{* *}$ & $45.00 \pm 2.39^{*}$ & $28.70 \pm 5.18^{* *}$ \\
\hline
\end{tabular}

$\mathrm{MDA}=$ Malondialdehyde. $\mathrm{SOD}=$ Superoxide dismutase. $\mathrm{CAT}=$ Catalase. $\mathrm{GSH}=$ Glutathione. Data are expressed as mean \pm SEM. $\mathrm{n}=5$. * Significant $(p<0.05)$ difference when compared to control. **Significant $(p<0.05)$ difference when compared to treatments with individual doses of vitamin $\mathrm{C}$ and $\mathrm{E}$

\section{Analysis of oxidative stress indices}

Liver malondialdehyde was evaluated according to Buege, and Aust, 1978 while superoxide dismutase was evaluated according to Sun and Zigma, 1978. Glutathione level was evaluated as reported by Ell man, 1959 while and catalase level was evaluated according to the method of Sinha, 1972.

\section{Statistical analysis}

Results are expressed as mean +SEM. Results were analyzed using one way analysis of variance (ANOVA) and statistical significance was set at $p<0.05$

\section{RESULTS AND DISCUSSION}

Treatment with individual doses of vitamins $\mathrm{C}$ and $\mathrm{E}$ significantly $(p<0.05)$ increased baseline liver and kidney SOD, CAT and GSH levels when compared to control. However, highest levels of SOD, CAT and GSH levels were obtained with pretreatment using combined doses of vitamins $\mathrm{C}$ and $\mathrm{E}$. The SOD, CAT and GSH values obtained with pretreatment using combined doses of vitamins $\mathrm{E}$ and $\mathrm{C}$ were significantly $(p<0.05)$ different when compared to their individual doses (Table
I and II). On the other hand, treatments with individual doses of vitamins $\mathrm{C}$ and $\mathrm{E}$ significantly $(p<0.05)$ decreased baseline liver and kidney MDA levels when compared to control. A combination of vitamin $\mathrm{C}$ and $\mathrm{E}$ further decreased baseline liver and kidney MDA levels to $0.31 \pm 0.03$ and $0.30 \pm 0.06 \mathrm{nmole} / \mathrm{mg}$ protein respectively. These decreases were significantly $(p<0.05)$ different when compared to MDA values obtained with treatments using individual doses of vitamins $\mathrm{C}$ and $\mathrm{E}$ (Table I and II)

On the contrary, this study observed significant $(\mathrm{p}<0.05)$ increases in liver and kidney MDA levels to $3.2 \pm 0.07$ and $2.65 \pm 0.01 \mathrm{nmole} / \mathrm{mg}$ protein respectively in rats treated with NVP/TDF when compared to control. However, pretreatments with individual doses of vitamins $\mathrm{C}$ and $\mathrm{E}$ prior to treatment with TDF/NVP decreased liver MDA levels to $1.73 \pm 0.06$ and $1.51 \pm 0.05 \mathrm{nmole} / \mathrm{mg}$ protein while kidney MDA levels were decreased to $1.35 \pm 0.03$ and $1.29 \pm 0.04 \mathrm{nmole} / \mathrm{mg}$ protein respectively. These decreased MDA values were significantly $(p<0.05)$ different when compared to MDA values obtained with TDF/NVP treatment. 


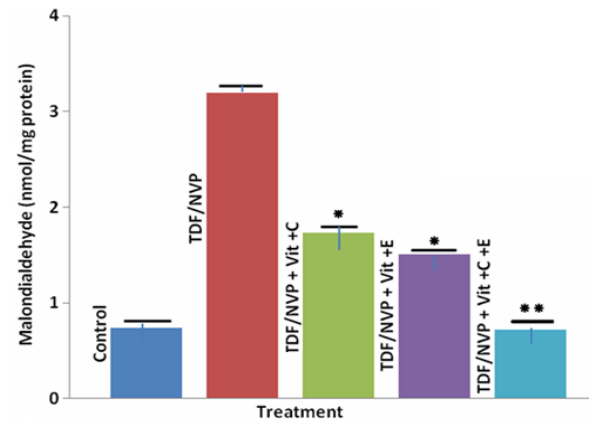

Figure 1. Effects of pretreatments with vitamins $\mathrm{C}$ and $\mathrm{E}$ on tenofovir/nevirapine-induced liver malondialdehyde level in male albino rats. * Significant $(p<0.05)$ difference when compared to tenofovir/nevirapine treatment. ${ }^{*}$ Significant $(p<0.05)$ difference when compared to pretreatments with individual doses of vitamins $\mathrm{C}$ and $\mathrm{E}$

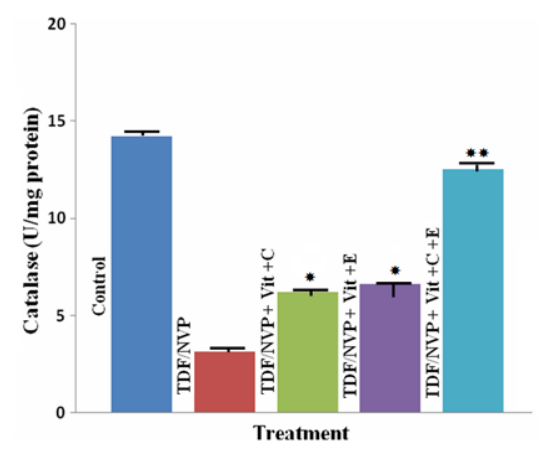

Figure 3. Effects of pretreatments with vitamins $\mathrm{C}$ and $\mathrm{E}$ on tenofovir/nevirapine-induced kidney catalase level in male albino rats. * Significant $(p<0.05)$ difference when compared to tenofovir/nevirapine treatment. ${ }^{*}$ Significant $(p<0.05)$ difference when compared to pretreatments with individual doses of vitamins $\mathrm{C}$ and $\mathrm{E}$

Further decreases in liver and kidney MDA levels to $0.72 \pm 0.08$ and $0.70 \pm 0.03 \mathrm{nmole} / \mathrm{mg}$ protein were obtained in rats pretreated with combined doses of vitamins $\mathrm{C}$ and $\mathrm{E}$. These decreased MDA values were significantly $(p<0.05)$ different when compared to MDA values obtained with pretreatments using individual doses of vitamins $\mathrm{C}$ and $\mathrm{E}$ (Figure 1 and 5).

Furthermore, treatment with TDF/NVP decreased liver SOD, CAT to $2.20 \pm 0.04$, $3.13 \pm 0.01, \mathrm{U} / \mathrm{mg}$ protein and GSH to

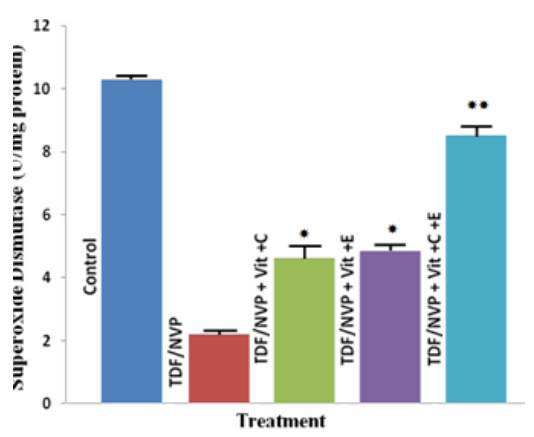

Figure 2. Effects of pretreatments with vitamins $\mathrm{C}$ and $\mathrm{E}$ on tenofovir/nevirapine-induced liver superoxide dismutase level in male albino rats. $*$ Significant $(p<0.05)$ difference when compared to tenofovir/nevirapine treatment. $* *$ Significant $(p<0.05)$ difference when compared to pretreatments with individual doses of vitamins $\mathrm{C}$ and $\mathrm{E}$

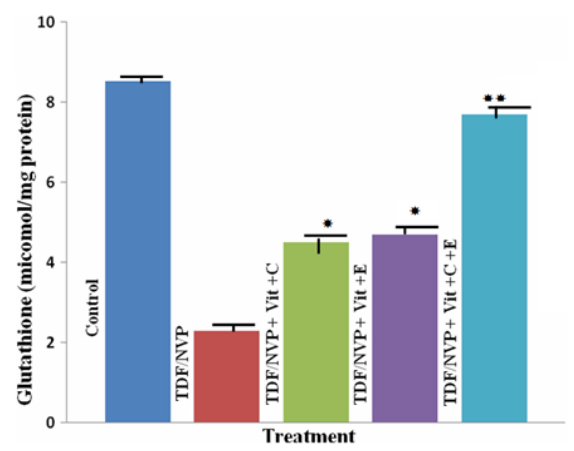

Figure 4.Effects of pre-treatments with vitamins $\mathrm{C}$ and $\mathrm{E}$ on tenofovir/nevirapine-induced liver glutathione level in male albino rats. * Significant $(p<0.05)$ difference when compared to tenofovir/nevirapine treatment. $* *$ Significant $(p<0.05)$ difference when compared to pretreatments with individual doses of vitamins $\mathrm{C}$ and $\mathrm{E}$

$2.23 \pm 0.06 \mu \mathrm{M} / \mathrm{mg}$ protrein while that of the kidneys were decreased to $3.00 \pm 0.02$, $3.21 \pm 0.01, \mathrm{U} / \mathrm{mg}$ protein $2.40 \pm 0.03 \mu \mathrm{M} / \mathrm{mg}$ protrein respectively. The observed decreases were significantly $(p<0.05)$ different when compared to control. However, pretreatments with individual doses of vitamins $\mathrm{C}$ and $\mathrm{E}$ significantly $(p<0.05)$ increased liver and kidney SOD, CAT and GSH levels when compare to TDF/NVP treated rats. Interestingly, pronounced increases in SOD, CAT and GSH levels in the liver and kidneys were obtained 


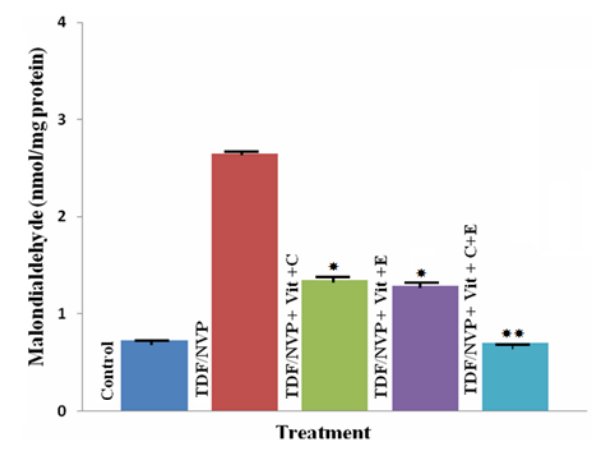

Figure 5. Effects of pretreatments with vitamins $\mathrm{C}$ and $\mathrm{E}$ on tenofovir/nevirapine-induced kidney malondialdehyde level in male albino rats. *Significant $(p<0.05)$ difference when compared to tenofovir/nevirapine treatments. $* *$ Significant $(p<0.05)$ difference when compared to pretreatments with individual doses of vitamins $\mathrm{C}$ and $\mathrm{E}$

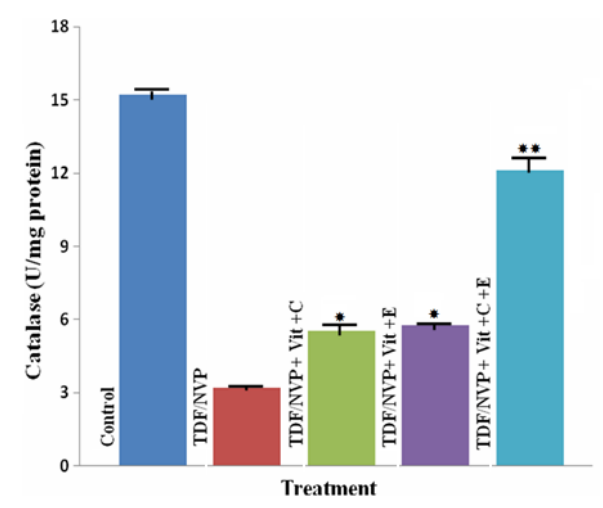

Figure 7. Effects of pretreatments with vitamins $\mathrm{C}$ and $\mathrm{E}$ on tenofovir/nevirapine-induced kidney catalase level in male albino rats. * Significant $(p<0.05)$ difference when compared to tenofovir/nevirapine treatment. $* *$ Significant $(p<0.05)$ difference when compared to pretreatments with individual doses of vitamins $\mathrm{C}$ and $\mathrm{E}$

with pretreatment using combined doses of vitamins $\mathrm{C}$ and $\mathrm{E}$. The observed increases in SOD, CAT and GSH levels were significantly $(p<0.05)$ different when compared to levels obtained with pretreatments using individual doses of vitamins $C$ and E. (Figure 2-8)

Cells have antioxidant defense mechanisms which include superoxide dismutase (SOD), catalase (CAT) and glutathione (GSH). These mechanisms prevent xenobiotic-induced oxidative damage. Studies

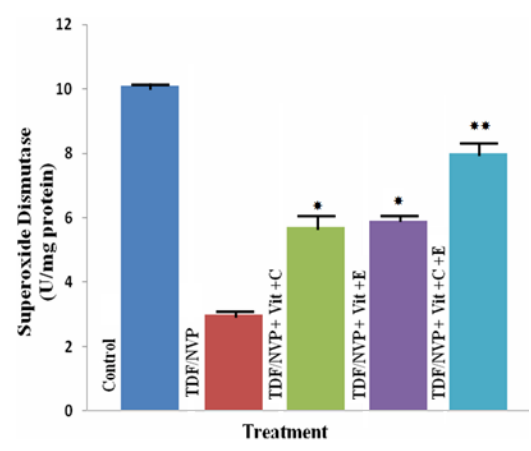

Figure 6. Effects of pretreatments with vitamins $\mathrm{C}$ and $\mathrm{E}$ on tenofovir/nevirapine-induced kidney superoxide dismutase level in male albino rats. *Significant $(p<0.05)$ difference when compared to tenofovir/nevirapine treatment. $* *$ Significant $(p<0.05)$ difference when compared to pretreatments with individual doses of vitamins $\mathrm{C}$ and $\mathrm{E}$

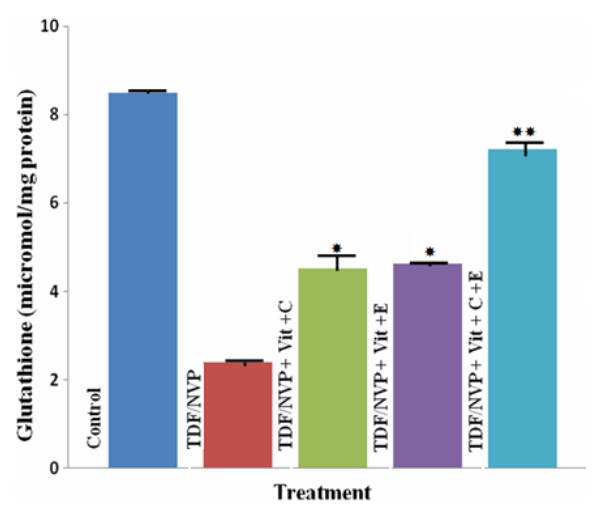

Figure 8. Effects of pretreatments with vitamins $\mathrm{C}$ and $\mathrm{E}$ on tenofovir/nevirapineinduced liver glutathione level in male albino rats. * Significant $(p<0.05)$ difference when compared to tenofovir/nevirapine treatments. ** Significant $(\phi<0.05)$ difference when compared to pretreatments with individual doses of vitamins $\mathrm{C}$ and $\mathrm{E}$

have shown that antioxidant defense could be depleted on exposure to drugs and toxic chemical substances (Sánchez, 2010). This study was aimed at investigating the effects of vitamins $\mathrm{C}$ and $\mathrm{E}$ on the baseline and TDF/NVP-induced kidney and liver levels of superoxide dismutase (SOD), glutathione (GSH), catalase (CAT) and malondialdehyde (MDA) in male albino rats. In this study, treatments with individual doses of vitamins $\mathrm{C}$ and $\mathrm{E}$ decreased liver and kidney MDA levels 
with increases in SOD, CAT and GSH levels. Most pronounced effects on these parameters were obtained with treatment using combined doses of these vitamins. This observation is in agreement with previous reports (Abraham $e t$ al., 2010). On the contrary, TDF/NVP treatment increased kidney and liver levels of MDA, but decreased SOD, CAT and GSH levels. The observations in TDF/NVP treated rats suggest signs of oxidative hepatorenal damage (Adaramoye et al., 2012). This could be attributed to oxidative stress induced by these agents in the kidney and liver of treated rats via the generation of oxidative radicals which might have led to the depletion of these antioxidants (Ramamoorthy et al., 2008). In the present study, observed depletion in kidney antioxidants could be attributed to the toxic effect of tenofovir on the kidneys of treated rats (Martínez et al., 2001) while decreases in antioxidant levels in the liver of TDF/NVP treated rats could be attributed to the toxic effect of nevirapine on the liver (Chu et al., 2010; Adikwu and Brambaifa, 2013)

Reduced glutathione (GSH) is the most prevalent non-protein thiol in animal cells. It is involved in the detoxification of a variety of electrophilic compounds and peroxides via catalysis by glutathione S-transferase (GST) and glutathione peroxidases (GPx) (Anderson, 1998; Mullineaux, and Creissen, 1997; Babiak., et al., 1998). SOD competes with nitric oxide for reaction with superoxide and prevents the generation of peroxynitrite, a potent oxidant that can modify proteins to form 3nitrotyrosine (Bowler, 1992). CAT catalyzes the dismutation of superoxide anion radicals to hydrogen peroxide which is degraded into a molecule of oxygen and water. The observed decreases in liver and kidney GSH, SOD, and CAT levels in TDF/NVP treated rats might have stimulated the accumulation of oxidative radicals leading to kidney and liver damage (Johnson and Giulivi, 2005; Saravanan et al., 2013). Malondialdehyde (MDA) is a biomarker of oxygen radical-induced lipid peroxidation (Fridovich, 1995). The observed increases in MDA levels in the liver and kidneys of TDFNVP treated rats are signs of lipid peroxidation. Studies have shown that lipid peroxidation can cause decrease in membrane fluidity and in the barrier functions of membranes. Also, it could produce oxidized products that could stimulate oxidative damage to cell structures and in toxicity process that could lead to cell death (Yin et al., 2011; Avery, 2011)

However, pretreatments with individual doses of vitamins $\mathrm{C}$ and $\mathrm{E}$ prior to treatment with TDF/NVP decreased kidney and liver MDA levels while SOD, CAT and GSH levels were increased. Most pronounced effects were obtained in rats pretreated with combined doses of these vitamins. The observed protective effects of vitamins $\mathrm{C}$ and $\mathrm{E}$ on TDF/NVP-induced hepatorenal oxidative stress are consistent with our previous study where these antioxidants attenuated ATV/rinduced oxidative stress in the kidneys of treated rats (Adikwu et al., 2016). Similarly, Sohini and Rana reported the protective effect of vitamin $\mathrm{C}$ on inorganic arsenic-induced oxidative stress in liver and kidneys of rats (Sohini and Rana , 2007). The finding in this study is also in agreement with the observations by Uboh and co-researchers who reported abrogation of gasoline vapor-induced liver injury by vitamins $\mathrm{C}$ and $\mathrm{E}$ (Uboh et al., 2012). In the present study, most pronounced mitigation observed in rats pretreated concurrently with vitamins $\mathrm{C}$ and $\mathrm{E}$ is in agreement with the work of Layachi and Kechrid who evaluated the protective effects of vitamins $\mathrm{C}$ and $\mathrm{E}$ on cadmium-induced oxidative liver injury in rats (Layachi and Kechrid, 2012). In addition, Aziz and coresearchers also reported synergistic effect with concurrent use of vitamins $\mathrm{C}$ and $\mathrm{E}$ on leadinduced liver and kidney injury in rats (Aziz et al., 2012)

Furthermore, decreases in kidney and liver MDA levels with increases in SOD, CAT and GSH levels observed with pretreatments using vitamins $\mathrm{C}$ and $\mathrm{E}$ could be attribute to the antioxidant effects of these vitamins and their abilities to regenerate or sustain antioxidant levels (Deavall et al., 2012). Vitamin $\mathrm{C}$ is a reducing agent that protects cellular components from oxidative damage. It acts as a scavenger of harmful oxygen derived species, such as the hydroxyl radical, hydrogen peroxide, and singlet oxygen (Sadi, 2012). It can also up-regulate the activities of other antioxidants such as SOD, GST, CAT and GSH (Packer,1997). Vitamin $\mathrm{E}$ is a scavenger 
of molecular oxygen, peroxide, hydroxyl radicals and atomic oxygen radicals (Kanter et al., 2009). It has been reported to either donate a hydrogen atom or possibly interacts with arachidonic acid to protect membrane lipid bilayer from lipid peroxidative damage. It can exert its protective effect by stabilizing the polypeptide chains of proteins. Studies have also shown that vitamin $E$ could sustain the intracellular levels of SOD, GST, CAT and GSH (Sert et al., 2000; El-hadjela et al., 2013). In this study, pronounced effects obtained with concurrent use of vitamins $\mathrm{E}$ and $\mathrm{C}$ could be attributed to additive or synergistic effect of these vitamins. Studies have shown that vitamin $\mathrm{C}$ has the ability to regenerate oxidized vitamin $\mathrm{E}$ molecules and thereby increasing its activity (Wirtz et al., 1996).

\section{CONCLUSION}

The present study showed that pretreatments with vitamins $C$ and $E$ mitigated tenofovir/nevirapine- induced hepatorenal oxidative stress. Mitigations were most pronounced in rats pretreated concurrently with these vitamins. The observations in this study could be attributed to the inhibitory effects of vitamins $\mathrm{C}$ and $\mathrm{E}$ on the oxidative effect of tenofovir/nevirapine in the liver and kidneys of treated rats.

\section{ACKNOWLEDGEMENTS}

The authors wish to acknowledge the technical assistance rendered by $\mathrm{Mr}$ Eze Iheukwumere of the Faculty of Pharmacy Madonna University Elele, Rivers State

\section{REFERENCES}

Abraham P., Kolli VK., and Rabi S. 2010. Melatonin attenuates methotrexateinduced oxidative stress and renal damage in rats, Cell Biochemistry and Function, 28; 5; 426-433

Adaramoye OA., Adewumi OM., Adesanoye OA., Faokule OO., Farombi EO., 2012. Effect of tenofovir, an antiretroviral drug, on hepatic and renal functional indices of Wistar rats: protective role of vitamin E," J. Basic and Clinical Phys and Pharma; 23; 2; 69-75,

Adaramoye OA., Adesanoye OA., Adewumi OM, and Akanni O., 2013. Studies on the toxicological effect of nevirapine, an antiretroviral drug, on the liver, kidney and testis of male Wistar rats," Human and Experimental Toxicology, 13; 676-685,

Adikwu E., Brambaifa N., 2013. Concentrationeffect, incidence and mechanism of nevirapine hepatotoxicity," Am. J. Pharmacology and Toxicology, $8 ; 1 ; 20-30$,

Adikwu E., Oputiri D., Oru-Bo P and Akuegbe ED., 2013. Nevirapine hepatotoxicity: implications of risk factors, $\mathrm{Am}$. J.Pharmacology and Toxicology $8 ; 2 ; 51-63$,

Adikwu E., Onyedenyifa JO, and Bibowei AA. 2006. Remedial Effects of Vitamins C and $\mathrm{E}$ on Atazanavir/Ritonavir-Induced Alterations in Biomarkers of Renal Function and Oxidative Stress indices of Male. Int J.Biomed Res, 7;4; 1993-2000

Adikwu E., Onyedenyifa OJ., and Newman K. S. 2016. Beneficial Effects of Vitamins C and $\mathrm{E}$ on Tenofovir and NevirapineInduced hepatorenal toxicity in male albino rats. Int. J. Biomedical Research 7 (4): 205-212

An Y., Xin H., Yan W., Zhou X. 2009. Amelioration of cisplatin-induced nephrotoxicity by pravastatin in mice, Experimental and Toxicological Pathology,63: 215-219

Anderson ME 1998. Glutathione: an overview of biosynthesis and modulation, ChemicoBiological Interactions, $111 ; 2: 1-14$

Arias IM., Jakoby WB., Popper H., Scachter D., Schafritz DA., 1997. Section 4 the organ: The hepatic microvascular system. The liver: Biology and Pathobiology, 3rd Ed. Lippincott Williams \& Wilkins, Available from: URL:

Avery SV. 2011. Molecular targets of oxidative stress," Biochemical Journal, 434; 2; 201210

Aziz FM., Maulood I, Chawsheen MAH. 2012. Effects of melatonin, vitamin $\mathrm{C}$ and $\mathrm{E}$ alone or in combination on lead-induced injury in liver and kidney organs of rats IOSR Journal of Pharmacy, 2; 5; 13-18

Babiak EM., Campello AP., Carnieri EGS, Oliveira MB.. 1998. Methotrexate, pentose cycle and oxidative stress," Cell Biochemistry and Function, 283; 93,

Bowler C., Montagu M.Y., and Irize D. 1992. Superoxide Dismutase and stress 
tolerance Annual Review of Plant Physio and Plant Mole Biol, 43; 83-116

British National Formulary 37, March, 1999

Buege JA. and Aust SD., 1978. Microsomal lipid peroxidation methods. Enzymol., 52: 302-310

Carr AC, and Frei B. 1999. Toward a new recommended dietary allowance for vitamin $\mathrm{C}$ based on antioxidant and health effects in humans," American J. Clinical Nutrition; 69; 6; 1086-1107

Chu KM., Boulle AM., Ford N., Goemaere E, Asselman V., and Van Cutsem G., 2010. Nevirapine-associated early hepatotoxicity: incidence, risk factors, and associated mortality in a primary care art programme in South Africa," PLoS ONE; ; , (2), Article ID e9183,

Combs J., and F. Gerald. The vitamins. 4 ed. Burlington: Elsevier Science; 2012

Deavall DG., Martin EA., Horner JM., and Roberts R. 2012. Drug-Induced Oxidative Stress and Toxicity. J. Toxicology Volume 2012, Article ID 645460, page. 13

El-hadjela DK. Zine, and Leila B., 2003. The beneficial effect of combined administration of vitamins $\mathrm{C}$ and $\mathrm{E}$ on renal function and selected parameters of antioxidant system in diabetic rats fed zinc-deficient diet, African J.Biotechnology, $12 ; 43 ; 6232-6240$,

Ellman GL. 1959 Tissue sulphydryl groups. Arch Biochem Biophys; 82: 70- 77.

Fridovich I. 1995. Superoxide radical and superoxide dismutases," Annual Review of Biochemistry, 64; 97-112,

Gallant JE., and Deresinski S 2003.Tenofovir disoproxil fumarate, Clinical Infectious Disease., 37: 944-950,

Hammer SM., Eron JJ., Reiss P., et al., 2008 . Antiretroviral treatment of adult HIV infection: 2008 recommendations of the international AIDS society USA panel. J.American Medical Association, 300, 55570 ,

Herrera C., and Barbas 2001. Vitamin E: action, metabolism and perspectives J.Physiology and Biochemistry, 57; 2; 43-56

Johnson F., and C. Giulivi, 2005. Superoxide dismutases and their impact upon human health," Molecular Aspects Medicine, 26; 340-352

Johnson VA., Brun-Ve'zinet F., Clotet B, 2004. Conway B,D'Aquila RT, Demeter LM. Update of the drugresistance mutations in HIV-1. Topics HIV Med, 12: 119-124

Junqueira LC., Carneiro J., 2003. Basic Histology Text \& Atlas. 10thEdition, New York: Lange Medical

Kanter M., Aksu B., Akpolat M., Tarladacalisir YT., Aktas C., Uysal H., 2009. Vitamin E Protects against Oxidative Damage Caused by Cadmium in the Blood of Rats,"European J. General Medicine, 6; 3, 154-160,

Layachi N and Kechrid Z. 2012. Combined protective effect of vitamins $C$ and $E$ on cadmium induced oxidative liver injury in rats, African J Biotechnology, 11; 93; 16013-160.

Li TS., Tubiana R., Katlama C., Calvez V., Ait Mohand H., Autran B. 1998. Long-lasting recovery in CD4 T-cell function andviral-load reduction after highly active antiretroviral therapy in advanced HIV-1 disease" Lancet, 351; 1682-6

Martínez E., Blanco JL., Arnaiz JA., et al., 2001. Hepatotoxicity in HIV-1-infected patients receiving nevirapine-containing antiretroviral therapy," AIDS, 15; 10; 1261-1268.

Mullineaux P. and Creissen GP. 1997. Glutathione reductase: regulation and role in oxidative stress Oxidative stress and the molecular biology of antioxidant defenses. Cold Spring Harbor Laboratory Press;

Packer L., Weber SU., Rimbach G. 2001. Molecular aspects of alphatocotrienol antioxidant action and cell signaling," J.Nutrition, 131; 2;369-373

Packer L. and Fuchs J, "Vitamin C in health and disease" Marcel Dekker, Inc., New York, Basel, Hong Kong (1997).

Raghavendra MJ., 2013. Instrumentation and control engineering functions of kidney \& artificial kidneys, Intern I Innov Res in Elec, Elec,;; 1 (1) :1-5

Ramamoorthy H., Abraham P. and Isaac B., 2014. Preclinical efficacy of melatonin in the amelioration of tenofovir 
nephrotoxicity by the attenuation of oxidative stress, nitrosative stress and inflammation in rats," J. Basic Clin Physio and Pharm, ; 25: 4: 387-399,

Ramamoorthy H., Abraham P., Isaac B. 2012. Oxidative stress, decreased activities of anti-oxidant enzymes, and neutrophil infiltration contribute to Tenofovir disoproxil fumarate induced renal damage in rats,"Inter Res of Pharm and Pharm 1; 10; 259-270

Sadi G., Eryilmaz N., Tütüncüoğlu E., Cingir S., Güray T. 2012. Changes in expression profiles of antioxidant enzymes in diabetic rat kidneys. Diabetes/Metabolism Research and Review,; 28, ; 3; 228-235,

Sánchez DJ. 2010. Effects of exposure to BDE-99 on oxidative status of liver and kidney in adult rats," Toxicology, 271; 51-6

Saravanan R., Rajendra N, Prasad NR. and Pugalendi KV. 2013 Effect of Piper betle leaf extract on alcohol toxicity in the rat brain. J.Med Food, 6; 3; 261-265

Sasse D., Spronitz UM., Mally IP. 1992. Liver architecture Ensyme,;:46: 8-32

Sert C., Elük MS., Akdaú Z., Ketanü MA., Nergüz Y. 2000. Radioprotective Effect of Vitamins C, E and Vitamin E + Glutathione on the Small Intestine and the Thyroid Gland in Rats Irradiated with X Rays, Turkey J. Medical Science,; 30; 417-425,

Sies H., "Oxidative Stress: Introductory Remarks. In: Oxidative Stress," Academic Press, London, 1985,
Sinha AK., 1972 Colorimetric Assay of catalase. Anal. Biochem.; 47. 2: 389-394.

Sohini SV., Rana S. 2007. Protective effect of ascorbic acid against oxidative stress induced by inorganic arsenic in liver and kidney of rat. Ind J Experiment Biology,; 45; 371-375

Sun M., Zigma S. 1978 An improved spectrophotometer assay of superoxide dismutase based on Epinephrine Antioxidation. Analytical Biochemistry.; 90: 81-89

Traber MG., Atkinson J., 2007. Vitamin E, antioxidant and nothing more.Free Rad. Biol. Med. 43: p. 4

Uboh FE., Ebong PE., Akpan HD., Usoh IT, 2012. Hepatoprotective effect of vitamins $\mathrm{C}$ and $\mathrm{E}$ against gasoline vapor-induced liver injury in male rats, Turk J Biol; 36 ; 217-223

Wirtz KW. 1996. Molecular mechanisms of signaling and membrane transport. Proceedings of the NATO study institute on molecular mechanism of signaling targeting. Island of Spetsai, Greece August 18-30,

Woodward CL., Hall AM., Williams IG., et al., 2009. Tenofovir associated renal and bone toxicity. Human immunodeficiency Medicine,: 10 :482-487

Yin Y., Xu L., Porter NA. 2011. Free radical lipid peroxidation: mechanisms and analysis," Chemical Reviens,; 111; 10; 5944-5972. 